Protocol

\title{
Title: Protocol for a literature review in investigating the potential of DevOps for public sector Information Technology delivery
}

Lesley Anne Kelly, School of Computing, University of Portsmouth, Portsmouth, UK.

\begin{abstract}
Background

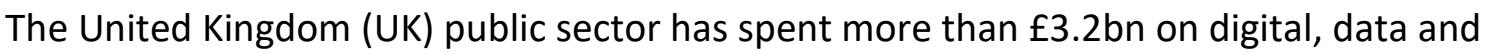
technology services since 2012. The UK public sector borrowing year ending March 2018 was at $f 41 \mathrm{bn}$. The debt at the end of February 2019 was at $£ 1785 \mathrm{bn}$ (Office of National Statistics, 2019) and because of this spiralling debt, the UK government had to implement austerity. Therefore, there was a need to address solutions to help the government implement austerity. For example, the NHS Digital (NHSD) annual report and accounts 2017 to 2018 reported an increase in expenditure for permanent staff, software development, IT maintenance and IT support. It is evident there is an increase in expenditure compared to their 2016 to 2017 report. This provides scope for reduction in expenditure.
\end{abstract}

\section{Objective}

This literature review aims to investigate if DevOps has the potential to transform public sector IT delivery and provide value for money to the taxpayer by reducing expenditure in software development, IT maintenance and IT support. We will also be reviewing the maturity of DevOps in its current form and address the benefits and downsides from a public sector perspective.

\section{Method}

Our literature review will apply the Preferred Reporting Items for Systematic Reviews and Meta-Analysis Protocol (PRISMA-P). We will accomplish a two-part study and apply thematic organisation of our literature. We will use databases recommended by the University of Portsmouth Library. Grey Literature will be included, but we will exclude untrustworthy literature, social media, broadcasting, and press media. Only literature with confirmed validity will be included for further research.

\section{Keywords}

DevOps, Public Sector, Information Technology, Software Development, Software Engineering, Software Delivery, Development, Operations.

\section{Introduction}

In 2018, the United Kingdom (UK) Government were working to find solutions to help balance the UK public sector financial books, so they implemented austerity. This austerity meant there were spending cuts which can have an impact on the way IT is delivered. We needed to take note of the Wanless Report (Wanless, 2002) which had mentioned the UK 
health service makes very poor use of ICT (Information, Communications and Technology). The report also stated there are examples of successful use of ICT at local level, but systems have typically been developed and installed in a piecemeal fashion. This prevents the effective integration and sharing of information across a wide range of health care providers. This is just one example of the problems in public sector IT delivery.

To help deliver IT in the public sector, thousands of private small and medium-sized enterprises (SMEs) are now signed up to provide their digital, data and technology services to the UK Government. This is known as a buying process which comes at a cost to the public sector (GOV.UK, 2018). For example, the NHS Digital (NHSD) Annual Report and Accounts 2017 to 2018 summarised the operating expenditure for permanent staff, IT maintenance and IT support yielded the highest percentage of the overall expenditure budget. The IT maintenance and IT support expenditure had increased by ten percent compared to the 2016 to 2017 report. The report also wrote, the work packages costs to provide short term specialist input, outsourced services and software development skills have increased to supplement internal teams. As a result, the capital expenditure had increased, particularly for internal and external software development, and this is also the same with the development expenditure (Health and Social Care Information Centre, 2018).

However, some teams in the NHSD organisation have successfully adopted DevOps and received the DevOps Industry Award 2017 as the best overall DevOps project in the public sector (NHS Digital, 2017). We can use this win as an example of successful DevOps implementation within the public sector.

This literature review aims to explore the potential of DevOps to resolve some of the issues within the public sector IT delivery. Also, the objective of this literature review is to investigate the existing benefits and downsides with DevOps, which will facilitate our research to see if it is able to transform the public sector IT delivery in a positive way.

\section{Background}

\section{What is the Public Sector?}

The Financial Conduct Authority (Public Sector Entity, 2019) defines the public sector as non-commercial administrative bodies responsible to the central governments, local governments, or local authorities.

The Cabinet Office (Cabinet Office. Public Bodies Handbook Part 1, n.d., p.5) defines a public body as a formally established organisation that is (at least in part) publicly funded to deliver a public or government service, though not as a ministerial department. The term refers to a wide range of entities that are within the public sector.

Most public bodies that operate within the UK are established and operated by the Government. (House of Commons Library. Briefing Paper, 2018, p.4). Some, such as the Parliamentary and Health Service Ombudsman, are set up by and directly accountable to Parliament. 
In the UK, the public sector has five sub sectors,

- $\quad$ Central government

- Local government

- Public non-financial corporations

- $\quad$ Public financial corporations (or public sector banks)

- $\quad$ Bank of England

The public sector is not the same as the private sector. The private sector comprises of companies that are usually owned by individuals and driven by profit. The private sector is funded by private money, whereas the public sector is funded by government taxes. However, some public sector organisations do outsource to the private sector.

As of 31 March 2017, there were 305 known public bodies in the UK with $£ 203$ billion gross resource expenditure (Cabinet Office, 2017, p.6).

\section{What is DevOps?}

The term DevOps was coined around 2009, when Patrick Debois named a conference, DevOps Days held in Ghent, Belgium.

DevOps is two words combined, Development and Operations. The key differences between Development and Operations are, the development side mainly creates the product, and the operation side focusses on keeping the product alive. The development subcategories may be designing, programming, and testing. The operations subcategories may be network management, service management and systems administration.

Whilst there is no single concise definition for DevOps. According to the DevOps Handbook by John Willis, Patrick Debois, Jez Humble, Gene Kim (Willis, Debois, Kim, 2016), they define DevOps is a technique that mostly importantly enables teams to work together in humane work conditions without the need for firefighting or heroics. Without DevOps, there can be several obstacles and other problems such as manual effort and handoffs which can result in days or weeks, or even months of waiting, the DevOps Handbook divulgated complications can result in negative impact to customers and by solving these impacts with DevOps, we can improve performance, not just from a technology perspective but from an organisational perspective as well. They know that if left unmanaged conflict can exist between development and operations resulting in slower time to market, increased outages, and technical debts. Their comparison of tightly and loosely coupled applications has explained that tightly coupled applications are common in large complex organisations often require long approval processes and often rely on manual testing. If we have high autonomy in small teams and keep the applications loosely coupled and contained to prevent global disruptions, then DevOps is ideal. 


\section{Literature Review Questions}

\section{Primary Questions}

RQ1. How mature is the DevOps concept and what evidence exists of its practical benefits?

RQ2. What are the main reported issues in adopting a DevOps approach and how can they be managed?

\section{Secondary Questions}

RQ3. What are the potential benefits and downsides of adopting DevOps in public sector IT?

RQ4. What are the cultural and organisational barriers to adopting DevOps public sector IT and how can they be managed?

\section{Our PICO Table}

\begin{tabular}{|l|l|l|l|}
\hline Population & Intervention & Comparison & Outcome \\
\hline $\begin{array}{l}\text { IT development and } \\
\text { support teams in the public } \\
\text { sector and private sector }\end{array}$ & DevOps & $\begin{array}{l}\text { DevOps against traditional } \\
\text { development/operations } \\
\text { split }\end{array}$ & $\begin{array}{l}\text { Quality and productivity of } \\
\text { the IT delivery }\end{array}$ \\
\hline
\end{tabular}

\section{Study Rationale}

The National Audit Office reported that commentators have focused on government's failure to deliver ICT projects to time, budget, and specification as well as the systemic reasons for these failures (National Audit Office, 2011, p.4). The NAO also conveyed the Government is considering new ways of working that could potentially introduce ICT that is more adaptive, can keep pace with changing business requirements and enable new systems to be brought into operation more quickly than historically has been the case.

The complications of the public sector IT projects seem to be exactly what DevOps intends to improve. The question is, can DevOps recover the UK's public sector IT delivery? Whilst DevOps is gaining popularity and recognition, we still need to grasp the fact if DevOps can strengthen IT delivery in the UK public sector, given the variety of challenges that arise within the UK's public sector and we also need to understand how the UK's public sector DevOps may differ from national and international private sector DevOps.

This literature review aims to apprehend how DevOps can or cannot improve IT delivery for the UK public sector and what the risks and benefits are and to measure DevOps maturity in its current form.

\section{Study Objectives}

The objective of the literature review is to identify, categorise, summarise, and synthesise literature around DevOps and know the presence and maturity for it. The benefits and risks of DevOps are not fully understood or entirely established, moreover the barriers and enablers of DevOps will take various forms, this literature review will provide informed 
knowledge around these entities. Our literature review will execute evidential claims study to clearly outline the DevOps benefits and risks and how these are managed.

\section{Methods and Analysis}

The EndNote Software (Clarivate Analytics, 2019) will be our data collection tool for the information management of this literature review.

All our inclusive and exclusive literature will be categorised using Endnote. Our bibliography will be built with EndNote. We also will record citations inside EndNote.

To ensure the success of our literature review, we will apply the PRISMA-P methodologies (PRISMA, 2019) and define,

\section{- $\quad$ Search terms}

- $\quad$ Appropriate searching tools for the web and databases

- Identifying valid key publications

- We will accomplish a two-part study,

- $\quad$ Title and Abstract review

- $\quad$ Full Text review

Our literature review will be organised and categorised thematically. We will start with general keywords and narrow down our search in a funnel manner. We will identify perceptions and theories that are relevant to our research problem.

We will discuss the methodology the literature used and undertake comparisons to seek any arguments that are similar. We will also aim to identify differences in results and discuss ways that our research may help resolve these differences.

We will apply the evidential claim study.

- What evidence do we have from the literature that supports their claim?

- What are the arguments given?

- $\quad$ Can the evidence be warranted?

- How reliable is the source of the evidence?

We will monitor our literature searches and identify core sources of information. We will also need to monitor new literature as they become available. Therefore, we will arrange our alerting tactics preferably email notifications with well-known databases as well as recursively revisiting the searches conserved in our database.

All planned searches will be recorded and tabulated, to allow these searches to be repeated.

\section{Search Strategy}

The search strategy will be designed to access both published and unpublished materials. These will be predominantly electronical to increase our accessibility to the literature, locally and internationally. Due to this we will need to efficiently use strategies to search, 
sort and manage the wider literature available to us. We will not be ruling out nonelectronic materials as if we are unable to obtain the literature electronically, we will obtain it in print if available.

The search will be refined in various ways to reduce the number of hits into manageable portions.

- $\quad$ Time Frame: Limited to 10 years' time span from current day

- $\quad$ Disciplines: Software Engineering and Software Development

- In English only

We will define a list of keywords. To use those keywords in the topic search.

- Where the keyword will appear in the title to produce fewer hits. First layer

- Where the keyword will appear in the abstract to more hits. Second layer

We will define our Boolean logic to widen the search to a larger number of sources when required.

Types of searching strategies

- $\quad$ Planning. Devising keywords and identifying appropriate tools

- $\quad$ Browsing. Exploratory search to identify key areas

- Methodical Searching. Once keywords and key areas are identified, we will conduct the methodical search and keep records of these searches

- $\quad$ Citations. Linking to other area of relevance by citations. We will organise citation indexing and backward chain from these indexes

- $\quad$ References. We will follow up references provided in the reference list of the source

We will select several trusted worldwide university repositories to obtain the academic literature, that may have not been published as well as those that have been published. We will use databases recommended by the University of Portsmouth Library.

List of primary databases to search

\begin{tabular}{|l|l|l|}
\hline Database Name & Database Description & Database Location \\
\hline Google Scholar & $\begin{array}{l}\text { Web search engine that indexes the } \\
\text { full text or metadata of scholarly } \\
\text { literature. }\end{array}$ & https://scholar.google.co.uk/ \\
\hline $\begin{array}{l}\text { University of } \\
\text { Portsmouth } \\
\text { Discovery Service }\end{array}$ & $\begin{array}{l}\text { Discovery tool from the University of } \\
\text { Portsmouth for books, journals, and } \\
\text { articles. }\end{array}$ & https://library.port.ac.uk/ \\
\hline $\begin{array}{l}\text { ACM Digital } \\
\text { Library }\end{array}$ & $\begin{array}{l}\text { Research, Discovery, and Networking } \\
\text { platform containing full collection of } \\
\text { all Association of Computing } \\
\text { Machinery. }\end{array}$ & https://dl.acm.org/dl.cfm \\
\hline $\begin{array}{l}\text { Engineering } \\
\text { Village }\end{array}$ & $\begin{array}{l}\text { Search this comprehensive database } \\
\text { of citations and abstracts from } \\
\text { engineering journals, conference } \\
\text { proceedings and technical reports. } \\
\text { Includes the Compendex database. }\end{array}$ & https://www.engineeringvillage.com/search/quick.url \\
\hline
\end{tabular}




\begin{tabular}{|c|c|c|}
\hline $\begin{array}{l}\text { Computers \& } \\
\text { applied sciences } \\
\text { complete }\end{array}$ & $\begin{array}{l}\text { Research and development spectrum } \\
\text { of the computing and applied } \\
\text { sciences disciplines. CASC provides } \\
\text { indexing and abstracts for academic } \\
\text { journals, professional publications, } \\
\text { and other reference sources. }\end{array}$ & $\begin{array}{l}\text { https://www.ebsco.com/products/research- } \\
\text { databases/computers-applied-sciences-complete }\end{array}$ \\
\hline Emerald insight & $\begin{array}{l}\text { Access to the full-text of thousands } \\
\text { of articles from hundreds of peer- } \\
\text { reviewed journals published by } \\
\text { Emerald. }\end{array}$ & https://www.emeraldinsight.com/ \\
\hline $\begin{array}{l}\text { IEEE Xplore digital } \\
\text { library }\end{array}$ & $\begin{array}{l}\text { A collection of journals, conference } \\
\text { proceedings and technical standards } \\
\text { published by the Institute of } \\
\text { Electrical and Electronics Engineers } \\
\text { (IEEE). }\end{array}$ & https://ieeexplore.ieee.org/Xplore/guesthome.jsp \\
\hline ScienceDirect & $\begin{array}{l}\text { Peer-reviewed journals, articles, } \\
\text { book chapters and open access } \\
\text { content. }\end{array}$ & https://www.sciencedirect.com/ \\
\hline
\end{tabular}

List of secondary databases to search (Grey Literature)

\begin{tabular}{|l|l|l|}
\hline Database Name & Database Description & Database Location \\
\hline OpenDOAR & $\begin{array}{l}\text { Open access database for research } \\
\text { and publications }\end{array}$ & https://v2.sherpa.ac.uk/opendoar/ \\
\hline GreyNet & $\begin{array}{l}\text { Grey Literature Network Service. } \\
\text { Potential issue: validity. }\end{array}$ & http://www.greynet.org/ \\
\hline Gartner & $\begin{array}{l}\text { The world's leading research and } \\
\text { advisory company. }\end{array}$ & https://www.gartner.com/home/feed \\
\hline
\end{tabular}

We will include grey literature that may not be published by recognised publishers and have not been part of the published approval processes. Grey literature is defined in the Cochrane Handbook, as literature that is not formally published (Cochrane Handbook for Systematic Reviews of Interventions, 2011).

We will search for businesses internal reports and documentations for their DevOps implementation processes and outlining their rationale and proposal in adopting DevOps. This will be considered as grey literature.

There are service manuals available from the UK government website:

https://www.gov.uk/service-manual/technology, we will read these manuals and assess if they could support DevOps or not. Additionally, the UK government digital service provides guidance for the technology code of practice from their website:

https://www.gov.uk/government/publications/technology-code-of-practice/technologycode-of-practice. We will read these as well and see if there is any relationship with DevOps.

\section{PRISMA-P, Preferred Reporting Items for Systematic Review and Meta- Analysis Protocols}

We will follow the PRISMA-P checklist. Appendix A. 
Full copies of the literature we have identified and those meeting the inclusion criteria of the PRISMA-P flow will be obtained for data synthesis. Other related literature to be identified through the reference list and bibliographic searches will be considered for data collection.

Our inclusion criteria:

- $\quad$ The nature of the literature

- The peer review process

- The popularity of the literature being cited

- The age of the literature

- The reputation of the author or authors

Our exclusion criteria:

- $\quad$ Predatory literature

- Social media

- $\quad$ Broadcasting (radio and television)

- $\quad$ Press and news media

\section{Data Synthesis}

For our data synthesis will apply the Joanna Briggs Institute critical appraisal tools to assess bias (Critical Appraisal Tools, 2019). We will also examine the effects of heterogeneity as there will have been different ways DevOps will have been implemented and will have produce different outcomes and effects.

We will undertake a narrative synthesis (Ryan, 2013) on our literature and synthesise accordingly following the PRISMA-P flow diagram inclusion and exclusion criteria. Our narrative synthesis will summarize and describe our evidential study base.

To evaluate the maturity levels for DevOps in the literature, we will adopt principles from the Capability Maturity Model (CMM) (Paulk, Curtis, Chrissis, Weber, 1993). However, there is not a known formal DevOps Maturity Model at the time of writing this protocol. We propose DevOps maturity can be measured in four distinct areas: Culture, Automation, Measurement, and Sharing, represented as the acronym CAMS (Pais, 2014 p. 28).

- $\quad$ Culture. Subcategory - collaboration, trust, non-blame, continuous, crossfunctional, transparent.

- $\quad$ Automation. Subcategory - self-service, release, provisioning, configuration, integration.

- $\quad$ Measurement. Subcategory - KPI's, performance metrics, people metrics, visualisation.

- $\quad$ Sharing. Subcategory - openness, improvements, collaboration, transparent.

We have fashioned our own DevOps Maturity Model shown below based upon principles of the CMM and CAMS acronyms. For clarity, high level indicates the above categories exist 
between 85 and 100 percent. Medium level indicates the categories exist between 45 and 84 percent and low level indicates less than 45 percent.

\begin{tabular}{|l|l|l|l|l|l|}
\hline & Base & Beginner & Intermediate & Advanced & Expert \\
\hline Culture & $\begin{array}{l}\text { None of the } \\
\text { subcategories } \\
\text { exists. }\end{array}$ & $\begin{array}{l}\text { Low level of trust } \\
\text { and high level of } \\
\text { blame. }\end{array}$ & $\begin{array}{l}\text { Medium level of } \\
\text { trust and low level } \\
\text { of blame. }\end{array}$ & $\begin{array}{l}\text { All subcategories } \\
\text { exist at medium } \\
\text { level. }\end{array}$ & $\begin{array}{l}\text { All subcategories } \\
\text { exist at high } \\
\text { level. }\end{array}$ \\
\hline Automation & $\begin{array}{l}\text { None of the } \\
\text { subcategories } \\
\text { exists. }\end{array}$ & $\begin{array}{l}\text { Low level of } \\
\text { automation in } \\
\text { place. }\end{array}$ & $\begin{array}{l}\text { Medium level of } \\
\text { automation in } \\
\text { place. }\end{array}$ & $\begin{array}{l}\text { All subcategories } \\
\text { exist at medium } \\
\text { level. }\end{array}$ & $\begin{array}{l}\text { All subcategories } \\
\text { exist at high } \\
\text { level. }\end{array}$ \\
\hline Measurement & $\begin{array}{l}\text { None of the } \\
\text { subcategories } \\
\text { exists. }\end{array}$ & $\begin{array}{l}\text { Some metrics are } \\
\text { available. }\end{array}$ & $\begin{array}{l}\text { Most metrics are } \\
\text { available. }\end{array}$ & $\begin{array}{l}\text { All subcategories } \\
\text { exist at medium } \\
\text { level. }\end{array}$ & $\begin{array}{l}\text { All subcategories } \\
\text { exist at high } \\
\text { level. }\end{array}$ \\
\hline Sharing & $\begin{array}{l}\text { None of the } \\
\text { subcategories } \\
\text { exists. }\end{array}$ & $\begin{array}{l}\text { Low level } \\
\text { collaboration is } \\
\text { active. }\end{array}$ & $\begin{array}{l}\text { Medium level } \\
\text { collaboration is } \\
\text { active. }\end{array}$ & $\begin{array}{l}\text { All subcategories } \\
\text { exist at medium } \\
\text { level. }\end{array}$ & $\begin{array}{l}\text { All subcategories } \\
\text { exist at high } \\
\text { level. }\end{array}$ \\
\hline
\end{tabular}

\section{Limitations}

As stated in our exclusion criteria, we will not be including these articles or papers in our literature review however we will allow academic blogs if we can prove authenticity of the author. We will not be including any literature that does not meet the criteria as defined in the PRISMA-P diagram.

We will narrow down search results and identify those that are most relevant to our research within the timescales. We will categorise these by differentiation, i.e. by group, by discipline and by source.

When we identify keywords, we will need to account for different phrases that similarly relate to the keywords identified as well as spelling differences.

We will consider synonyms using a table or grid. To identify alternative to the primary keywords, i.e.

\begin{tabular}{|l|l|}
\hline Keyword & Synonyms \\
\hline Software & Program, Application, System. Computer \\
\hline Development & Evolution, Refinement, Advancement, Maintenance \\
\hline
\end{tabular}

Due to the growth of open access, there is a growing number of predatory publishers. These predatory publishers accept any article regardless of their credibility with the aim to make as much profit as they can. Unfortunately, these articles can be of poor quality and misleading. To support us avoid these predatory traps, we will only use trusted sources. We will also work with our research outputs team within the University of Portsmouth Library to validate the article if we suspect the journal to be predatory.

DevOps is an emerging concept and the popularity for it is rising exponentially fast. This rapid exponential rise could collapse any day. There is no guarantee that DevOps will continue to gain popularity in the near or far future. Given that DevOps is relatively new currently in organisations, it is certainly relatively new in the UK public sector. Therefore, we 
will need to reflect that we may not find much specific literature in this subject and may need to consider alternative strategies.

Some literature may not be available electronically, and we may have to use the University of Portsmouth inter-library loans, and this is currently averaging one week from request.

We might not be able to locate exactly the literature we want and could result us to recategorize our findings.

\section{References}

Cabinet Office. (2017). Public Bodies 2017. Retrieved from:

https://assets.publishing.service.gov.uk/government/uploads/system/uploads/attachment_ data/file/663615/PublicBodies2017.pdf

Cabinet Office. Public Bodies Handbook Part 1. (n.d.). Classification of Public Bodies: Guidance for Departments. Retrieved from:

https://assets.publishing.service.gov.uk/government/uploads/system/uploads/attachment_ data/file/519571/Classification-of-Public_Bodies-Guidance-for-Departments.pdf

Clarivate Analytics, EndNote X9. (2019). Retrieved from the Clarivate Analytics Website: https://clarivate.libguides.com/endnote_training/users/enx9

Cochrane Handbook for Systematic Reviews of Interventions, The Cochrane Collaboration, version 5.1.0. (2011). Retrieved from the Cochrane Website: https://handbook-5 1.cochrane.org/front_page.htm

Critical Appraisal Tools, Joanna Briggs Institute. (2019). Retrieved from the Joanna Briggs Institute Website: http://joannabriggs.org/research/critical-appraisal-tools.html

GOV.UK. Government spend on digital services passes f3bn mark. (2018). Retrieved from the GOV.UK Website: https://www.gov.uk/government/news/government-spend-ondigital-services-passes-3bn-mark

GRADE Handbook, Introduction to GRADE handbook. (2013). Retrieved from the Grade Pro Website: https://gdt.gradepro.org/app/handbook/handbook.html

House of Commons Library. Briefing Paper. (2018). Public Bodies. Retrieved from: https://researchbriefings.files.parliament.uk/documents/CBP-8376/CBP-8376.pdf

Health and Social Care Information Centre (HSCIC) Annual Report and Accounts 2017-18. (2018). Retrieved from the NHS Digital website: https://digital.nhs.uk/about-nhsdigital/corporate-information-and-documents/nhs-digital-s-annual-reports-andaccounts/nhs-digital-annual-report-and-accounts-2017-to-2018\#read-the-annual-report National Audit Office. Report by the Comptroller and Auditor General. (2011). Information and Communications Technology in Government Landscape Review. Retrieved from: https://www.nao.org.uk/wp-content/uploads/2011/02/1011757.pdf 
NHS Digital. Best Public Sector DevOps team awarded to NHS Digital. (2017). Retrieved from the NHS Digital Website: https://digital.nhs.uk/news-and-events/news-archive/2017-newsarchive/best-public-sector-devops-team-awarded-to-nhs-digital

Office for National Statistics. Public sector finances, UK: February 2019. (2019). Retrieved from the Office for National Statistics Website:

https://www.ons.gov.uk/economy/governmentpublicsectorandtaxes/publicsectorfinance/b ulletins/publicsectorfinances/november2018

Pais, M. (2014). Introducing DevOps to the Traditional Enterprise [eMag issue]. InfoQ, Issue 14.

Paulk, M., Curtis, B., Chrissis, M., Weber. C. (1993). Capability Maturity Model for Software, Version 1.1 (CMU/SEI-93-TR-024 ESC-TR-93-177). USA: Carnegie Mellon University.

PRISMA, PRISMA for systematic review protocols (PRISMA-P). (2019). Retrieved from the PRISMA Website: http://www.prisma-statement.org/Extensions/Protocols.aspx

Public Sector Entity. (2019). Retrieved from the Financial Conduct Authority Website: https://www.handbook.fca.org.uk/handbook/glossary/G2242.html

Ryan, R., Cochrane Consumers and Communication Review Group: Data Synthesis and Analysis. (2013). Retrieved from the Cochrane Consumers and Communication Website: http://cccrg.cochrane.org

Wanless Derek. (2002). Securing our Future Health: Taking a Long-Term View, Final Report. London: HM Treasury.

Willis, J., Debois, P., Kim, G. (2016). The DevOps Handbook. USA: IT Revolution Press. 


\section{Appendix A}

PRISMA-P (Preferred Reporting Items for Systematic review and Meta-Analysis Protocols) 2015 checklist: recommended items to address in a systematic review protocol*

\begin{tabular}{|c|c|c|}
\hline Section and topic & Item No & Checklist item \\
\hline \multicolumn{3}{|l|}{ ADMINISTRATIVE INFORMATION } \\
\hline \multicolumn{3}{|c|}{ Title: } \\
\hline Identification & la & Identify the report as a protocol of a systematic review \\
\hline Update & $1 \mathrm{~b}$ & If the protocol is for an update of a previous systematic review, identify as such \\
\hline Registration & 2 & If registered, provide the name of the registry (such as PROSPERO) and registration number \\
\hline \multicolumn{3}{|r|}{ ( } \\
\hline Contact & $3 \mathrm{a}$ & $\begin{array}{l}\text { Provide name, institutional affiliation, e-mail address of all protocol authors; provide physical mailing address of } \\
\text { corresponding author }\end{array}$ \\
\hline Contributions & $3 \mathrm{~b}$ & Describe contributions of protocol authors and identify the guarantor of the review \\
\hline Amendments & 4 & $\begin{array}{l}\text { If the protocol represents an amendment of a previously completed or published protocol, identify as such and list changes; } \\
\text { otherwise, state plan for documenting important protocol amendments }\end{array}$ \\
\hline \multicolumn{3}{|r|}{ P } \\
\hline Sources & $5 \mathrm{a}$ & Indicate sources of financial or other support for the review \\
\hline Sponsor & $5 \mathrm{~b}$ & Provide name for the review funder and/or sponsor \\
\hline Role of sponsor or funder & $5 \mathrm{c}$ & Describe roles of funder(s), sponsor(s), and/or institution(s), if any, in developing the protocol \\
\hline \multicolumn{3}{|l|}{ INTRODUCTION } \\
\hline Rationale & 6 & Describe the rationale for the review in the context of what is already known \\
\hline Objectives & 7 & $\begin{array}{l}\text { Provide an explicit statement of the question(s) the review will address with reference to participants, interventions, } \\
\text { comparators, and outcomes (PICO) }\end{array}$ \\
\hline \multicolumn{3}{|l|}{ METHODS } \\
\hline Eligibility criteria & 8 & $\begin{array}{l}\text { Specify the study characteristics (such as PICO, study design, setting, time frame) and report characteristics (such as years } \\
\text { considered, language, publication status) to be used as criteria for eligibility for the review }\end{array}$ \\
\hline Information sources & 9 & $\begin{array}{l}\text { Describe all intended information sources (such as electronic databases, contact with study authors, trial registers or other } \\
\text { grey literature sources) with planned dates of coverage }\end{array}$ \\
\hline Search strategy & 10 & $\begin{array}{l}\text { Present draft of search strategy to be used for at least one electronic database, including planned limits, such that it could be } \\
\text { repeated }\end{array}$ \\
\hline \multicolumn{3}{|r|}{ TP } \\
\hline Data management & $11 \mathrm{a}$ & Describe the mechanism(s) that will be used to manage records and data throughout the review \\
\hline Selection process & $11 \mathrm{~b}$ & $\begin{array}{l}\text { State the process that will be used for selecting studies (such as two independent reviewers) through each phase of the } \\
\text { review (that is, screening, eligibility and inclusion in meta-analysis) }\end{array}$ \\
\hline Data collection process & $11 \mathrm{c}$ & $\begin{array}{l}\text { Describe planned method of extracting data from reports (such as piloting forms, done independently, in duplicate), any } \\
\text { processes for obtaining and confirming data from investigators }\end{array}$ \\
\hline Data items & 12 & $\begin{array}{l}\text { List and define all variables for which data will be sought (such as PICO items, funding sources), any pre-planned data } \\
\text { assumptions and simplifications }\end{array}$ \\
\hline Outcomes and prioritization & 13 & $\begin{array}{l}\text { List and define all outcomes for which data will be sought, including prioritization of main and additional outcomes, with } \\
\text { rationale }\end{array}$ \\
\hline Risk of bias in individual studies & 14 & $\begin{array}{l}\text { Describe anticipated methods for assessing risk of bias of individual studies, including whether this will be done at the } \\
\text { outcome or study level, or both; state how this information will be used in data synthesis }\end{array}$ \\
\hline \multirow[t]{4}{*}{ Data synthesis } & $15 \mathrm{a}$ & Describe criteria under which study data will be quantitatively synthesised \\
\hline & $15 \mathrm{~b}$ & $\begin{array}{l}\text { If data are appropriate for quantitative synthesis, describe planned summary measures, methods of handling data and } \\
\text { methods of combining data from studies, including any planned exploration of consistency (such as } \mathrm{I}^{2} \text {, Kendall's } \tau \text { ) }\end{array}$ \\
\hline & $15 \mathrm{c}$ & Describe any proposed additional analyses (such as sensitivity or subgroup analyses, meta-regression) \\
\hline & $15 \mathrm{~d}$ & If quantitative synthesis is not appropriate, describe the type of summary planned \\
\hline Meta-bias(es) & 16 & Specify any planned assessment of meta-bias(es) (such as publication bias across studies, selective reporting within studies) \\
\hline Confidence in cumulative evidence & 17 & Describe how the strength of the body of evidence will be assessed (such as GRADE) \\
\hline
\end{tabular}

From: Shamseer L, Moher D, Clarke M, Ghersi D, Liberati A, Petticrew M, Shekelle P. Stewart L, PRISMA-P Group. Preferred reporting items for systematic review and meta-analysis protocols (PRISMA-P) 2015: elaboration and explanation. BMJ. 2015 Jan 2;349(jan02 1): :7647. 